\title{
When do parents and child health professionals agree on child's psychosocial problems? Cross-sectional study on parent-child health professional dyads
}

Mathilde R. Crone ${ }^{1,4^{*}}$, Elke Zeij| ${ }^{2}$ and Sijmen A. Reijneveld ${ }^{3,4}$

\begin{abstract}
Background: About one third of all parents have concerns about their child's psychosocial development. Agreement between child health professionals (CHPs) and parents about such concerns may improve treatment adherence and outcomes. This study investigates which child, parenting and/or environmental stressors are associated with (dis) agreement in concerns regarding psychosocial problems in children, in parent-CHP dyads.
\end{abstract}

Methods: During routine child health assessments, data were collected from a sample of children aged 14 months to 12 years $(n=3,870)$. CHPs registered the psychosocial problems that they identified, and parents reported their concerns. Child psychosocial stressors were measured with the ITSEA/CBCL, and the child's history of psychosocial problems. Environmental stressors referred to stressful family/contextual situations in the past year, and parenting stressors to perceived parenting efficacy.

Results: The CHPs and parents disagreed on $36.4 \%$ of the children. CHPs based their identification of problems mainly on children's history of past problem $(\mathrm{OR}=5.85,95 \% \mathrm{Cl}=4.74-7.22)$. Parental concerns were most likely in case of an increased ITSEA/CBCL score (OR $=7.69, \mathrm{Cl}=5.39-10.97)$. CHP-parent agreement was more likely in case of a combination of child psychosocial, parenting and environmental stressors ( $\mathrm{OR}=35.58, \mathrm{Cl}=24.11-52.48)$. Parental concerns not confirmed by the CHP were associated with higher educated parents, originating from an industrialized country, and younger children. The CHP-identified problems not confirmed by parental concerns were associated with older children.

Conclusion: Agreement between CHPs and parents is associated with a co-occurrence of child, parenting and environmental stressors. Improved agreement between CHP and parents will increase the likelihood of shared decision-making regarding follow-up care and compliance with advice.

Keywords: Identification, Mental health, Parental concerns, Agreement, Stressful events, Vulnerability, Preschool child, Child

\section{What is new?}

Children requiring assistance according to both the parents and child health professionals (CHPs) more often had child stressors in combination with parenting and/or environmental stressors. Disagreements between CHPs and parents were due to 1) parents

\footnotetext{
* Correspondence: m.r.crone@lumc.nl

'Department of Public Health and Primary Care, Leiden University Medical Center, Public Health and Primary Care, P.O. Box 96002300 RC Leiden, The Netherlands

${ }^{4}$ TNO, Leiden, The Netherlands

Full list of author information is available at the end of the article
}

being more worried about preschool children and current problems, and 2) CHPs identifying more problems in school-aged children, and chronic or persisting problems.

\section{Background \\ Psychosocial problems are highly prevalent among children [1], have a negative and often persistent in- fluence on children's daily lives, and may lead to ad- verse outcomes later on [2-5]. Early identification of psychosocial problems is an important first step in}


preventing severe problems later in life, and may improve the child's prognosis [6].

In the Netherlands, community pediatric services are important for the early identification of psychosocial problems in children. Comparable to professionals working in community pediatric services in the USA, child health professionals (CHPs) working in Dutch services routinely offer preventive care to all children aged $0-19$ years. About $80-90 \%$ of all children undergo about ten CHP assessments until the age of 4 years, and about three assessments during their school career.

CHPs identify psychosocial problems in about $25 \%$ of the children that visit them [7]. However, the sensitivity of CHPs in identifying children with behavioral and/or emotional problems based on an independent assessment (e.g. diagnostic interviews or validated screening instruments) is relatively low [7, 8]. CHP identification is generally based on information provided by parents. About $30 \%$ of parents have minor to severe concerns regarding the psychosocial development of their child $[9,10]$. These concerns are significantly associated with elevated problem scores on behavioral screening tools [11-13]. Therefore, if these concerns are disclosed, the likelihood of CHPs identifying problems in these children will be much higher $[6,14,15]$. However, even when disclosed, CHPs do not always confirm all parental concerns and, vice versa, not all parents agree with all the CHPidentified problems [10]. This discrepancy between $\mathrm{CHP}$ and parents hampers appropriate and effective care [16].

Few studies have simultaneously investigated professionals' and parents' viewpoints to explore potential reasons for this discrepancy [14, 17]. Studies examining agreement mainly focus on agreement based on the assessment instruments completed by parents, adolescents and teachers; [18] generally, they do not examine the agreement between parents and professionals regarding concerns. In addition, an increased score on these assessment instruments does not imply the presence of parental or CHP concerns and, conversely, a score in the normal range does not imply an absence of concerns $[10,15,19]$.

The present study used data of parents-CHP dyads to explore the agreement between the identified psychosocial problems in children and the factors influencing this agreement. In line with assessment frameworks of child development, stressors related to the child, parents, and family and environmental context, were studied [20]. The aim was to explore whether these stressors are associated with parent$\mathrm{CHP}$ (dis)agreement and whether a combination of these stressors is more strongly related to agreement.

\section{Methods}

\section{Study sample}

Between October 2002 and June 2003 we recruited a national sample of community pediatric services: in total 25 services participated. Ten services had preventive health assessments with children aged $0-4$ years and 15 services with children aged 4-12 years. Each service was asked to interview a random sample of at least 100 children that visited the CHP for a routine preventive health assessment in four age groups: i) 14 months, ii) 3 years 9 months, iii) 5/6 years, and iv) 8-12 years.

From the 5,611 eligible children, $85.1 \%(n=4,776)$ participated; the main reason for non-response was refusal to participate. For 447 children the parents did not complete the questionnaire, whereas the CHP did; these children more often had mothers with a lower educational level (55.0 \% for children with CHP data only versus $38.2 \%$ for children with both CHP and parent data), were from a non-industrialized country $(36.0 \%$ versus $14.0 \%)$, came from a one-parent household (14.4\% versus $7.5 \%)$, and were younger ( $48.1 \%$ versus $36.1 \%$ aged $\leq 4$ years). There were no differences in the CHPidentified psychosocial problems. For 162 children no data were available from the CHP whereas the parents had completed the questionnaire; these children did not differ from children with data from both informants regarding the reported concerns of the parents (no background characteristics available).

Included in the study were children for whom parents and CHPs had filled out the questionnaire $(n=4,168)$. For the analyses, data were used only from those children who were not yet being treated for psychosocial problems (95\%) and who had no missing answers on the variables under investigation. This resulted in a total sample of 3,870 children.

\section{Procedure}

Data were collected as part of the preventive health assessment; a questionnaire was mailed to the parents together with the invitation to attend the assessment. Parents completed the questionnaire and returned it to the researchers in a sealed envelope (CHPs were not permitted to view the questionnaire): $84 \%$ of the parents completed the questionnaire prior to the assessment and $16 \%$ completed it afterwards.

After each child's physical examination, during a standardized interview with the parents the CHP obtained information on the child's/family background and on mental health history. After this interview and the health assessment of the child, CHPs registered the psychosocial problems they had identified (all CHPs received prior instruction from the research team about how to register the socio-economic characteristics and the identified psychosocial problems). In a separate questionnaire, CHPs 
were asked about their general use of screening tools to identify psychosocial problems.

Translations of the Child Behavior CheckList (CBCL) and additional questionnaires were provided in English, Arabic and Turkish. Also, Turkish and Moroccan interpreters were available to assist Turkish and Moroccan parents in completing the questionnaire. Parents from Surinam and the Netherlands Antilles (former Dutch colonies) generally speak the Dutch language. Bias due to interpretation of the questionnaire by the translators was prevented as far as possible by discussing the meaning of each item on the questionnaires with them.

\section{Measures}

CHP-parent agreement concerned the identification of problems by the CHP, and the concerns of parents about the psychosocial problems of the child.

For the CHP-identified psychosocial problems, the CHP filled out the following question after each assessment: 'Does the child have a psychosocial problem, at this moment?' (yes, no) and scored the type of identified problem(s) on a pre-coded list. The CHP was instructed to code problems such as sleeping or eating problems as problems only when they suspected that they were related to psychosocial problems. These questions were comparable to the ones used in an earlier study [7].

Parental concerns about their child's psychosocial problems were obtained by a parental concerns questionnaire regarding social, behavioral and/or emotional problems of their child in the past 12 months, for which they felt the child needed professional assistance. The responses were 'no concerns', 'some concerns' or 'serious concerns'. Parents were categorized as: 1) either having no concerns, or 2) having some to severe concerns about at least one of the problems.

Agreement between CHP-identified problems and parental concerns was categorized as: 1) no CHP-identified problems and no parental concerns, 2) no CHPidentified problems, but parental concerns, 3) CHPidentified problems, but no parental concerns, and 4) both CHP-identified problems and parental concerns.

Child psychosocial stressors referred to an increased psychosocial total problems score of the child, and a history of psychosocial problems. The psychosocial total problems score was measured by the Infant Toddler Social and Emotional Assessment (ITSEA), and the CBCL for ages $1.5-5$ years and ages $6-18$ years [21-24]. These instruments assessed the parent's report on the child's behavioral and emotional symptoms during the preceding 6 months. In the group of infants aged 14 months, parents completed the ITSEA: a well-validated questionnaire for parents with a child aged 12-36 months, consisting of 166 items measuring 17 syndrome scales [23, 24].
For the present study, parents filled out the items of 12 syndrome scales (activity/impulsivity, aggressive behavior, depressive/withdrawn, general anxiety, separation distress, inhibition to novelty, sleeping problems, negative emotionality, eating problems, tactile sensitivity, and attention problems). They represent three broadband groups (Externalizing, Internalizing and Dysregulation) and one total problems scale, and has a good factor structure and acceptable internal consistency [25]. Parents of children aged 3 years 9 months, and $5 / 6$ years, completed the CBCL 1.5-5, which consists of 100 problem items. Parents of 8-12 year old children completed the CBCL 6-18 consisting of 113 problem items [21, 22]. In the present study, only the Total Problems scores of the ITSEA and the CBCL were used. Children were allocated to a normal or a clinical range based on the cut-off points of the USA normative sample which, according to the $\mathrm{CBCL}$ developers, are also valid for Dutch children [26].

Regarding history of problems, the CHP asked parents whether the child had received earlier assistance from a professional because of psychosocial problems (no/yes). The CHP also indicated whether, in a former CHP contact, psychosocial problems were registered in the child's file (no/yes). Children were categorized as: 1) having no history of psychosocial problems, or 2) having a history.

Parenting stressors were measured by 10 statements on parenting efficacy (with answers ranging from $1=$ totally disagree to $4=$ totally agree): i.e. whether parents experience parenting as a burden, are satisfied about how they parent, and always know what to do in various parenting situations. This standardized measure is frequently used by the Netherlands Institute for Social Research to assess parents' experience with parenting, and is significantly correlated with parenting styles and the need of parents for parenting assistance [27]. A Cronbach's $\alpha$ of 0.71 indicated a reasonable reliability. A sum score was calculated for each parent (scale from 1 to 4 ). As the distribution was skewed to the right, the sum score was dichotomized into 1) parents with sufficient parenting efficacy (score $\geq 3$ ), and 2) parents with less parenting efficacy (score $<3$ ).

Family and environmental stressors were asked during the interview between the parents and the CHP, and concerned several pre-formulated family and environmental life events of the child during the past 12 months based on the Coddington Life Event Questionnaire; this questionnaire has been validated for the Netherlands and several other countries [28-30]. Events ranged from the birth of a brother/sister, divorce, illness of family members, death of a family member, to unemployment and low income (below or at the poverty line). Children were categorized as 1) having a maximum of one stressful situation, or 2) more than one. 


\section{Child, family and CHP background characteristics}

Child and family background assessed by the CHP were: gender, age, ethnicity, and highest educational level. Ethnicity was based on the country of origin of the biological parents of the children. Children were coded as originating from an industrialized country when both parents were indigenous Dutch, or born in another country that resembles the Dutch population in socio-economic status and cultural position (Statistics Netherlands: www.cbs.nl): defined as countries that are a member of the Organisation for Economic Co-operation and Development (OECD), with the exception of Turkey. Children were coded as originating from a non-industrialized country when at least one of the parents was born in Turkey, or in a country that is not a member of the OECD. Educational level was determined by the highest level of education completed by the parents and classified according to the International Standard Classification of Education: 1) low level, no, primary or lower secondary education; 2) average level, upper secondary education or post-secondary non-tertiary education; and 3) high level, recognized tertiary education [31]. As the identification of problems by the CHP is partly influenced by the use of screening tools and is likely to have an impact on the CHP-parent agreement, the CHPs were asked about their use of screening questionnaires to identify psychosocial problems during routine preventive health assessments: 1) never, 2) when indicated, 3) for every child.

\section{Statistical analysis}

First, we examined the characteristics of children and CHP-parent agreement (frequencies and Cohen's Kappa), and the association between these characteristics and the variables of agreement, i.e. identification and concerns. Univariate and multivariate multilevel logistic regression analyses were performed to assess whether stressors and background characteristics were significantly associated with CHP identification and with parental concerns. Then, these logistic analyses were repeated including (instead of the individual factors) the combination of child, parenting and context stressors in the model, i.e. 1) no child, parenting or environmental stressors, 2) no child stressors, but parenting or environmental stressors, 3) child stressors, but no parenting or environmental stressors, 4) child and parenting or environmental stressors. Multinomial regression analyses were conducted to determine whether the combination of these groups of stressors led to more parent-CHP agreement than the separate groups. All data were analyzed with the SPSS.

\section{Results}

In total, $63 \%$ of the participating children were aged 512 years, about $50 \%$ were girls and $80 \%$ were of Dutch origin or from an industrialized country (Table 1).

In $17.5 \%$ of the children, the CHP identified psychosocial problems and in $38.5 \%$ parents had concerns about their child's psychosocial development for which they felt professional assistance is needed. CHPs most frequently identified internalizing problems (6.7 \%), followed by other developmental problems (5.8\%), and externalizing problems (5.0 \%). Parents most frequently had concerns about the child's behavioral $(23.1 \%)$ and emotional development $(14.0 \%)$. In $63.6 \%$ of the children, parents and CHPs agreed as to whether or not the child had a problem. Children of parents that completed the questionnaire after the CHP visit did not differ in agreement rate from those who completed the questionnaire in advance, i.e. $64.4 \%$ versus $63.4 \%$.

In case of disagreements, these most often referred to children for whom parents had concerns that were not confirmed by the CHP (Table 2). In particular, parental concerns regarding the behavioral development of the child were less frequently identified by the CHP. This was also reflected by the lower inter-rater reliability between CHPs and parents regarding behavioral problems $($ Kappa $=.066$; standard error $=.014)$. The inter-rater reliability for internalizing problems was .109 (.019), and for social problems .144 (.025). Overall the inter-rater reliability scores indicated that the agreement between parents and CHPs was just slightly higher than could be expected from chance alone.

Table 3 shows that (univariately) an increased CBCL/ ITSEA score, a history of problems, exposure to environmental stressors, lower parenting efficacy, school-aged children, boys, children from a non-industrialized country, lower educational level, and the use of screening instruments by CHPs, were significantly associated with CHP identification of psychosocial problems. In a multivariate regression analysis all these factors (except environmental stressors and ethnicity) remained significant predictors of CHP identification. A history of psychosocial problems was the strongest predictor of problem identification by CHPs. CHP-identified problems were most frequently observed in children who showed stressors in both the child, and the parenting and/or environmental domain. Children exposed only to parenting and/or environmental stressors were not identified with psychosocial problems more often than children without such stressors.

Parental concerns about their child's psychosocial development were more likely when the child had an increased CBCL/ITSEA score, a history of problems, environmental stressors, less effective parents, and parents with a higher educational level. The strongest predictor 
Table 1 Child and family characteristics associated with CHP-identified psychosocial problems and parental concerns among children aged $0-12$ years

\begin{tabular}{|c|c|c|c|c|c|}
\hline & Total & CHP identified psyc & hosocial problems & Parental concerns & \\
\hline & $\% \mathrm{n}, n=3,870$ & No $\% \mathrm{n}, n=3,193$ & Yes $\% \mathrm{n}, n=677$ & No $\% \mathrm{n}, n=2,388$ & Yes $\% \mathrm{n}, n=1,482$ \\
\hline Total Sample & & 82.5 & 17.5 & 61.7 & 38.3 \\
\hline Child: CBCL/ITSEA problem score & & & $* * *$ & & $* * *$ \\
\hline No clinical score & 95.3 & 97.0 & 87.4 & 98.7 & 89.9 \\
\hline Clinical score & 4.7 & 3.0 & 12.6 & 1.3 & 10.1 \\
\hline Child: history of problems & & & $* * *$ & & $* * *$ \\
\hline No & 84.3 & 90.2 & 56.3 & 88.9 & 76.7 \\
\hline Yes & 15.7 & 9.8 & 43.7 & 11.1 & 23.3 \\
\hline Environmental: Life events & & & $* *$ & & $* * *$ \\
\hline No & 88.9 & 89.9 & 84.2 & 90.5 & 86.2 \\
\hline Yes & 11.1 & 10.1 & 15.8 & 9.5 & 13.8 \\
\hline Parenting: Parenting efficacy & & & $* * *$ & & $* * *$ \\
\hline Efficacy & 77.1 & 79.0 & 68.1 & 82.5 & 68.5 \\
\hline Low efficacy & 22.9 & 21.0 & 31.9 & 17.5 & 31.5 \\
\hline Gender & & & $* * *$ & & \\
\hline Girl & 51.1 & 52.6 & 44.0 & 52.0 & 49.7 \\
\hline Boy & 48.9 & 47.4 & 56.0 & 48.0 & 50.3 \\
\hline Ethnicity & & & $*$ & & \\
\hline Industrialized country & 81.3 & 82.0 & 78.0 & 79.9 & 80.5 \\
\hline Non-Industrialized country & 19.7 & 18.0 & 22.0 & 20.1 & 19.4 \\
\hline Age & & & $* * *$ & & $* * *$ \\
\hline 14 months & 18.8 & 20.7 & 9.6 & 18.1 & 19.8 \\
\hline 3 years 9 months & 18.2 & 18.9 & 14.6 & 16.3 & 21.3 \\
\hline $5 / 6$ years & 34.3 & 31.3 & 48.2 & 33.6 & 35.4 \\
\hline $8-12$ years & 28.8 & 29.0 & 27.6 & 32.0 & 23.5 \\
\hline Educational level & & & $* * *$ & & \\
\hline Low & 38.0 & 36.5 & 45.2 & 39.3 & 35.8 \\
\hline Average & 36.0 & 36.5 & 33.4 & 35.3 & 37.2 \\
\hline High & 24.3 & 25.2 & 19.8 & 23.6 & 25.4 \\
\hline Unknown & 1.7 & 1.7 & 1.6 & 1.7 & 1.6 \\
\hline CHP's use of screening instruments & & & *** & & *** \\
\hline Never & 83.0 & 83.9 & 78.9 & 83.0 & 83.0 \\
\hline When indicated & 11,3 & 11.0 & 12.4 & 11.1 & 11.5 \\
\hline At each assessment & 5.7 & 5.1 & 8.7 & 5.9 & 5.5 \\
\hline Combination child, parenting, environmental stressors & & & $* * *$ & & *** \\
\hline Not in child and parenting/context & 60.1 & 65.5 & 34.3 & 68.6 & 46.4 \\
\hline Not in child but in parenting/context & 21.2 & 22.3 & 16.2 & 19.3 & 24.3 \\
\hline In child, but not in parenting/context & 10.1 & 6.9 & 25.4 & 7.7 & 14.1 \\
\hline Both in child and parenting/context & 8.6 & 5.3 & 24.1 & 4.4 & 15.2 \\
\hline
\end{tabular}

*Differences in child and family characteristics between children with and without CHP-identified psychosocial problems and between parents with and without concerns regarding development of the child: ${ }^{*}=p<0.05 ;{ }^{* *}=p<0.01,{ }^{* * *}=p<0.001$ 
Table 2 Child and family characteristics associated with (dis)agreement between CHP and parents on psychosocial problems in children aged $0-12$ years

\begin{tabular}{|c|c|c|c|c|}
\hline & $\begin{array}{l}\text { CHP-parent agree on child } \\
\text { having no problems \%n, } \\
n=2,086\end{array}$ & $\begin{array}{l}\text { Parents have concerns } \\
\text { but CHP identifies no } \\
\text { problems } \% n, n=1,107\end{array}$ & $\begin{array}{l}\text { Parents have no } \\
\text { concerns, CHP } \\
\text { identifies problems } \\
\% n, n=302\end{array}$ & $\begin{array}{l}\text { Parents and CHP } \\
\text { agree that child has } \\
\text { problems \% n, } \\
n=375\end{array}$ \\
\hline Total sample & 53.9 & 28.6 & 7.8 & 9.7 \\
\hline Child: CBCL/ITSEA problem score & $* * *$ & & & \\
\hline No clinical score & 99.1 & 93.0 & 95.7 & 80.8 \\
\hline Clinical score & 0.9 & 7.0 & 4.3 & 19.2 \\
\hline Child: history of problems & $* * *$ & & & \\
\hline No & 92.4 & 86.1 & 65.2 & 49.1 \\
\hline Yes & 7.6 & 13.9 & 34.8 & 50.9 \\
\hline Environmental: Life events & $* * *$ & & & \\
\hline No & 91.4 & 86.9 & 84.1 & 84.3 \\
\hline Yes & 8.6 & 13.1 & 15.9 & 15.7 \\
\hline Parenting: Parenting efficacy & $* * *$ & & & \\
\hline Higher efficacy & 83.0 & 71.5 & 78.5 & 59.7 \\
\hline Lower efficacy & 17.0 & 28.5 & 21.5 & 40.3 \\
\hline Gender & ** & & & \\
\hline Girl & 53.0 & 52.0 & 45.7 & 42.7 \\
\hline Boy & 47.0 & 48.0 & 54.3 & 57.3 \\
\hline \multicolumn{5}{|l|}{ Ethnicity } \\
\hline Industrialized country & 81.7 & 82.5 & 77.2 & 78.7 \\
\hline Non-Industrialized country & 18.3 & 17.5 & 22.8 & 21.3 \\
\hline Age & $* * *$ & & & \\
\hline 14 months & 19.6 & 22.8 & 7.9 & 10.9 \\
\hline 3 years 9 months & 16.9 & 22.9 & 12.3 & 16.5 \\
\hline $5 / 6$ years & 31.4 & 31.3 & 48.7 & 47.7 \\
\hline $8-12$ years & 32.1 & 23.1 & 31.1 & 24.8 \\
\hline Educational level & ** & & & \\
\hline Low & 38.1 & 33.3 & 47.7 & 43.2 \\
\hline Average & 36.0 & 37.8 & 30.8 & 35.5 \\
\hline High & 24.2 & 27.2 & 19.5 & 20.0 \\
\hline Unknown & 1.7 & 1.7 & 2.0 & 1.3 \\
\hline CHP's use of screening instruments & $* *$ & & & \\
\hline Never & 83.6 & 84.5 & 79.1 & 78.7 \\
\hline When indicated & 11.1 & 10.9 & 11.3 & 13.3 \\
\hline At each assessment & 5.4 & 4.6 & 9.6 & 8.0 \\
\hline $\begin{array}{l}\text { Combination child, parenting, environmental } \\
\text { stressors }\end{array}$ & *** & & & \\
\hline Not in child and parenting/context & 71.8 & 53.7 & 46.0 & 24.8 \\
\hline Not in child but in parenting/context & 19.8 & 27.1 & 16.6 & 16.0 \\
\hline In child, but not in parenting/context & 5.4 & 9.8 & 23.5 & 26.9 \\
\hline Both in child and parenting/context & 3.1 & 9.5 & 13.9 & 32.3 \\
\hline
\end{tabular}

*Differences in child and family characteristics between categories of agreement between CHP and parents the child: ${ }^{*}=p<0.05 ;{ }^{* *}=p<0.01,{ }^{* * *}=p<0.001$ 
Table 3 Child/family characteristics associated with CHP-identified psychosocial problems or parental concerns in children aged $0-12$ years

\begin{tabular}{|c|c|c|c|c|c|c|}
\hline & \multicolumn{3}{|c|}{ CHP identifies problems } & \multicolumn{3}{|c|}{ Parents have concerns } \\
\hline & $\begin{array}{l}\% \text { CHP identified } \\
\text { problems }\end{array}$ & $\begin{array}{l}\text { Unadjusted OR } \\
(95 \% \mathrm{Cl}) n=3,870\end{array}$ & $\begin{array}{l}\text { Adjusted OR } \\
(95 \% \mathrm{Cl}) n=3,870\end{array}$ & $\begin{array}{l}\% \text { parental } \\
\text { concern }\end{array}$ & $\begin{array}{l}\text { Unadjusted OR } \\
(95 \% \mathrm{Cl}) n=3,870\end{array}$ & $\begin{array}{l}\text { Adjusted OR } \\
(95 \% \text { Cl) } n=3,870\end{array}$ \\
\hline \multicolumn{7}{|l|}{ Child: CBCL/TSEA problem score } \\
\hline No clinical score\$ & 16.0 & 1 & 1 & 36.0 & 1 & 1 \\
\hline Clinical score & 47.2 & $4.66(3.37-6.44)$ & $3.43(2.41-4.89)$ & 82.8 & $8.63(6.17-12.07)$ & $7.69(5.39-10.97)$ \\
\hline \multicolumn{7}{|l|}{ Child: history of problems } \\
\hline No\$ & 11.7 & 1 & 1 & 34.9 & 1 & 1 \\
\hline Yes & 48.6 & $6.56(5.29-8.14)$ & $5.85(4.75-7.21)$ & 56.7 & $2.47(2.05-2.98)$ & $2.28(1.91-2.73)$ \\
\hline \multicolumn{7}{|l|}{ Environmental: life events } \\
\hline No\$ & 16.6 & 1 & 1 & 37.2 & 1 & 1 \\
\hline Yes & 24.8 & $1.60(1.25-2.05)$ & $1.20(0.92-1.59)$ & 47.3 & $1.54(1.23-1.93)$ & $1.55(1.21-1.99)$ \\
\hline \multicolumn{7}{|l|}{ Parenting: Parenting efficacy } \\
\hline Higher efficacy\$ & 15.4 & 1 & 1 & 34.0 & 1 & 1 \\
\hline Lower efficacy & 24.4 & $1.73(1.43-2.09)$ & $1.28(1.05-1.56)$ & 52.7 & $2.17(1.88-2.51)$ & $1.92(1.65-2.23)$ \\
\hline \multicolumn{7}{|l|}{ Gender } \\
\hline Girl\$ & 15.1 & 1 & 1 & 37.2 & 1 & 1 \\
\hline Boy & 20.0 & $1.38(1.18-1.61)$ & $1.21(1.02-1.43)$ & 39.5 & $1.10(0.96-1.25)$ & $0.98(0.85-1.12)$ \\
\hline \multicolumn{7}{|l|}{ Ethnicity } \\
\hline Industrialized country\$ & 16.8 & 1 & 1 & 38.4 & 1 & 1 \\
\hline Non-Industrialized country & 20.6 & $1.27(1.18-1.61)$ & $0.87(0.66-1.14)$ & 37.8 & $0.99(0.83-1.18)$ & $0.78(0.64-0.94)$ \\
\hline \multicolumn{7}{|l|}{ Age } \\
\hline 14 months\$ & 9.0 & 1 & 1 & 40.4 & 1 & 1 \\
\hline 3 years 9 months & 14,1 & $1.67(1.04-2.68)$ & $1.39(0.89-2.16)$ & 44.7 & $1.20(0.97-1.48)$ & $1.14(0.91-1.42)$ \\
\hline $5 / 6$ years & 24.6 & $3.20(2.03-5.04)$ & $2.49(1.55-4.00)$ & 39.6 & $0.96(0.77-1.21)$ & $0.90(0.71-1.14)$ \\
\hline $8-12$ years & 16.8 & $2.40(1.53-3.77)$ & $1.61(1.00-2.58)$ & 31.4 & $0.67(0.53-0.85)$ & $0.60(0.47-0.76)$ \\
\hline \multicolumn{7}{|l|}{ Educational level } \\
\hline Low\$ & 20.8 & 1 & 1 & 36.1 & 1 & 1 \\
\hline Average & 16.2 & $0.72(0.59-0.88)$ & $0.85(0.69-1.05)$ & 39.5 & $1.04(0.66-1.64)$ & $1.25(1.05-1.50)$ \\
\hline High & 14.3 & $0.56(0.44-0.72)$ & $0.70(0.53-0.91)$ & 40.0 & $1.16(0.96-1.40)$ & $1.39(1.13-1.71)$ \\
\hline Unknown & 16.9 & $0.74(0.41-1.34)$ & $0.62(0.35-1.08)$ & 36.9 & $1.14(0.98-1.34)$ & $1.10(0,66-1.82)$ \\
\hline \multicolumn{7}{|l|}{$\begin{array}{l}\text { CHP's use of screening } \\
\text { instruments }\end{array}$} \\
\hline Never\$ & 16.6 & 1 & 1 & 38.3 & 1 & 1 \\
\hline When indicated & 19.3 & $1.16(0.81-1.66)$ & $1.53(1.10-2.14)$ & 39.2 & $1.06(0.75-1.50)$ & $1.00(0.73-1.37)$ \\
\hline At each assessment & 26.6 & $1.85(1.27-2.70)$ & $1.38(0.86-2.22)$ & 36.5 & $0.93(0.71-1.22)$ & $0.90(0.72-1.14)$ \\
\hline
\end{tabular}


Table 3 Child/family characteristics associated with CHP-identified psychosocial problems or parental concerns in children aged $0-12$ years (Continued)

\begin{tabular}{|c|c|c|c|c|c|c|}
\hline $\begin{array}{l}\text { Combination child, parenting, } \\
\text { environmental stressors }\end{array}$ & & & $\&$ & & & \& \\
\hline $\begin{array}{l}\text { Not in child and parenting/ } \\
\text { context\$ }\end{array}$ & 10.0 & 1 & 1 & 29.6 & 1 & 1 \\
\hline $\begin{array}{l}\text { Not in child but in } \\
\text { parenting/context }\end{array}$ & 13.4 & $1.33(1.01-1.76)$ & $1.28(0.96-1.71)$ & 43.8 & $1.88(1.59-2.22)$ & $2.11(1.77-2.51)$ \\
\hline $\begin{array}{l}\text { In child, but not in } \\
\text { parenting/context }\end{array}$ & 43.9 & $6.40(4.90-8.38)$ & $6.20(4.72-8.13)$ & 53.3 & $2.78(2.21-3.48)$ & $3.11(2.47-3.91)$ \\
\hline $\begin{array}{l}\text { Both in child and parenting/ } \\
\text { context }\end{array}$ & 49.1 & $8.16(6.22-10.70)$ & $7.84(5.85-10.51)$ & 68.1 & $5.20(4.26-6.36)$ & $6.24(5.04-7.73)$ \\
\hline
\end{tabular}

was an increased score on the CBCL/ITSEA. Fewer concerns were reported by parents of children aged 8-12 years and by parents from non-industrialized countries. Similar to CHP-identified problems, parental concerns were most likely to occur in children with child stressors combined with parenting and/or environment stressors.

The agreement between parents and CHPs on the presence of problems was strongly associated with a combination of child, and parenting and/or environmental stressors. When parents had concerns not confirmed by the CHP, this association was weaker. These nonconfirmed children were relatively more often exposed to only parenting and/or environmental stressors, while no child psychosocial stressors were reported. Also, these children were more often from higher educated families, and less often aged 8-12 years or from nonindustrialized countries. In contrast, children with CHPs identified problems not confirmed by parental concerns more often were aged 8-12 years (Table 4).

\section{Discussion}

This study indicates that there are disagreements between CHP-identified problems and parental concerns about the child's psychosocial problems, in one of every three children. Mutual agreement on the need for professional assistance was more likely to occur if the child had just started school, showed child stressors due to the manifestation of symptoms, a history of psychosocial problems in combination with environmental stressors, and lower parenting efficacy. Parental concerns most often concerned worries about the child's behavioral development, and were most likely to be present in the case of a clinical ITSEA/CBCL score, and in toddlers. However, concerns were frequently not confirmed by the CHP in younger children from industrialized countries and in higher educated families. Children identified by CHPs more often had a history of problems and tended to be school-aged. In children aged 8-12 years, CHPs more often perceived problems, whereas their parents had fewer or no concerns.

In line with our expectations, a combination of child, parenting and environmental stressors increases the agreement between professional and parent. Problems are more likely to be apparent in these children, and studies on either parents or professionals show that both recognize severe problems more easily [13, 32]. In contrast, when CHP and parents disagree, stressors cooccur less frequently and nearly $50 \%$ reported no stressors. About $25 \%$ of the children with parental concerns not confirmed by the CHP had parenting and/or environmental stressors but no child stressors.

Child stressors differ to some extent between parents and CHPs. CHPs seem to focus more on history or the persistence of problems, whereas current problems (as expressed by the CBCL/ITSEA score) appear to disturb parents the most, which is also reflected in lower parenting efficacy. In particular, this parental burden and appraisal of problems relate to the help-seeking behavior of parents and child mental health services use [33, 34]. However, differences in perspectives on child problems can also be caused by reporter bias: e.g. in the present study, parents completed the CBCL/ITSEA and the parenting efficacy scale, whereas the CHPs registered the history of problems and life events. Nevertheless, the CHP registration and identification was based on parental reports (during the interviews), implying less risk of reporter bias with regard to the history of problems and life events.

Generally, parents with younger children tend to have more concerns, whereas CHPs do not always confirm these concerns $[9,10,35]$. This may be related to the finding that the accuracy of parental concerns for detecting mental health problems is lower when the child is 
Table 4 Multinomial regression analysis comparing CHP-parent agreement on the child having no problems with CHP-parent agreement on the child having problems, and CHP-parent disagreement with the child having problems

\begin{tabular}{|c|c|c|c|c|}
\hline & \multicolumn{4}{|c|}{ Reference: CHP-parent agreement on the child having no psychosocial problems $(n=2,086)$} \\
\hline & $\begin{array}{l}\text { \% children on which } \\
\text { CHP and parent agree } \\
\text { there are problems }\end{array}$ & $\begin{array}{l}\text { Parents have concerns } \\
\text { but CHP identifies no } \\
\text { problems OR }(95 \% \text { Cl)\# } \\
n=1,107\end{array}$ & $\begin{array}{l}\text { Parents have no concerns } \\
\text { but CHP identifies } \\
\text { problems OR }(95 \% \text { Cl)\# } \\
n=302\end{array}$ & $\begin{array}{l}\text { Parents and CHP agree } \\
\text { that child has problems } \\
\text { OR }(95 \% \mathrm{Cl}) \# n=375\end{array}$ \\
\hline \multicolumn{5}{|l|}{$\begin{array}{l}\text { Child: CBCL/TTSEA total } \\
\text { problem score }\end{array}$} \\
\hline No clinical score\$ & 8.2 & 1 & 1 & 1 \\
\hline Clinical score & 40.0 & $8.57(5.03-14.61)$ & $4.44(2.10-9.37)$ & $22.38(12.56-39.88)$ \\
\hline \multicolumn{5}{|l|}{ Child: history of problems } \\
\hline No\$ & 5.6 & 1 & 1 & 1 \\
\hline Yes & 31.4 & $1.93(1.51-2.46)$ & $5.78(4.31-7.76)$ & $11.26(8.53-14.87)$ \\
\hline \multicolumn{5}{|l|}{$\begin{array}{l}\text { Environmental: Stressful } \\
\text { situations }\end{array}$} \\
\hline No\$ & 9.2 & 1 & 1 & 1 \\
\hline Yes & 13.7 & $1.77(1.36-2.30)$ & $1.55(1.05-2.27)$ & $1.50(1.03-2.20)$ \\
\hline \multicolumn{5}{|l|}{ Parenting: Parenting efficacy } \\
\hline Higher efficacy\$ & 7.5 & 1 & 1 & 1 \\
\hline Lower efficacy & 17.0 & $1.82(1.52-2.19)$ & $1.11(0.81-1.52)$ & $2.45(1.87-3.20)$ \\
\hline \multicolumn{5}{|l|}{ Gender } \\
\hline Girl\$ & 8.1 & 1 & 1 & 1 \\
\hline Boy & 11.4 & $0.96(0.83-1.12)$ & $1.25(0.97-1.61)$ & $1.20(0.93-1.53)$ \\
\hline \multicolumn{5}{|l|}{ Ethnicity } \\
\hline Industrialized country\$ & 9.4 & 1 & 1 & 1 \\
\hline Non-Industrialized country & 11.0 & $0.78(0.62-0.98)$ & $0.86(0.61-1.21)$ & $0.66(0.47-0.93)$ \\
\hline \multicolumn{5}{|l|}{ Age } \\
\hline 14 months\$ & 5.6 & 1 & 1 & 1 \\
\hline 3 years 9 months & 8.8 & $1.15(0.91-1.44)$ & $1.66(0.97-2.84)$ & $1.46(0.92-2.31)$ \\
\hline $5 / 6$ years & 13.5 & $0.84(0.68-1.04)$ & $3.25(2.04-5.17)$ & $2.55(1.71-3.82)$ \\
\hline $8-12$ years & 8.4 & $0.58(0.46-0.73)$ & $1.83(1.13-2.96)$ & $1.00(0.65-1.55)$ \\
\hline \multicolumn{5}{|l|}{ Educational level } \\
\hline Low\$ & 11.0 & 1 & 1 & 1 \\
\hline Average & 9.5 & $1.25(1.04-1.51)$ & $0.85(0.63-1.14)$ & $1.14(0.85-1.53)$ \\
\hline High & 8.0 & $1.43(1.17-1.74)$ & $0.76(0.54-1.07)$ & $1.05(0.74-1.47)$ \\
\hline Unknown & 7.7 & $1.24(0.68-2.25)$ & $0.81(0.32-2.05)$ & $0.60(0.21-1.74)$ \\
\hline \multicolumn{5}{|l|}{$\begin{array}{l}\text { CHP's use of screening } \\
\text { instruments }\end{array}$} \\
\hline Never\$ & 9.2 & 1 & 1 & 1 \\
\hline When indicated & 11.5 & $0.93(0.73-1.19)$ & $1.35(0.90-2.02)$ & $1.61(1.10-2.35)$ \\
\hline At each assessment & 13.5 & $0.91((0.64-1.30)$ & $1.27(0.80-2.01)$ & $1.03(0.64-1.67)$ \\
\hline
\end{tabular}


Table 4 Multinomial regression analysis comparing CHP-parent agreement on the child having no problems with CHP-parent agreement on the child having problems, and CHP-parent disagreement with the child having problems (Continued)

\begin{tabular}{|c|c|c|c|c|}
\hline $\begin{array}{l}\text { Combination child, parent, } \\
\text { environmental stressors }\end{array}$ & & \& & \& & $\&$ \\
\hline $\begin{array}{l}\text { Not in child and } \\
\text { parenting/context\$ }\end{array}$ & 4.0 & 1 & 1 & 1 \\
\hline $\begin{array}{l}\text { Not in child but in } \\
\text { parenting/context }\end{array}$ & 7.3 & $2.08(1.73-2.51)$ & $1.21(0.85-1.73)$ & $2.51(1.77-3.58)$ \\
\hline $\begin{array}{l}\text { In child, but not in } \\
\text { parenting/context }\end{array}$ & 25.8 & $2.76(2.07-3.67)$ & $6.26(4.39-8.91)$ & $15.39(10.84-21.86)$ \\
\hline $\begin{array}{l}\text { Both in child and } \\
\text { parenting/context }\end{array}$ & 36.4 & $5.05(3.61-7.07)$ & $6.67(4.28-10.40)$ & $35.58(24.11-52.48)$ \\
\hline
\end{tabular}

$\$=$ Reference group

\# Adjusted for other parent, child, environmental stressors and child, family, and CHP background characteristics

Bold: significant ORs, $p<0.05$

\& adjusted for child, family, CHP background characteristics

younger [9]. Parents with concerns sometimes have misconceptions regarding what is the 'normal' development for a child $[6,36]$. The present study suggests that these unconfirmed parental concerns might also express other problems related to parenting ability and environmental stressors; this implies that the CHP's decision not to recognize them as child psychosocial problems might be adequate. Also, during the encounter with the CHP, parents with younger children may less often express their concerns compared with parents of older children, because they are unaccustomed to asking for help regarding the mental health problems of their child, or believe that it is too early to detect psychosocial problems $[6,37]$. However, CHPs may not always be accurate in recognizing and discussing these concerns, even when disclosed by the parents.

In contrast to our findings, Blanchard et al. found that parents were more often concerned about problems in school-aged children than in younger children [38]. The discrepancy between the latter study and ours might be related to differences in collecting data on parental concerns. Their questions differed between younger and older children and also referred to worries about learning difficulties; these were prominent concerns in their school-aged children but were not included as concerns in the present study.

Similar to Brugman et al. we found that CHP identification was most prevalent in children aged $5 / 6$ years who had just started elementary school [7]. Their problems may reflect the psychosocial problems that a child encounters when entering the school setting. Moreover, schools are frequently the first setting in which children can be observed among their peers by both professionals and parents. This might explain the finding that parents and CHPs were more likely to agree on problems related to children in this age group.

Parents of children aged 8-12 years with CHP-identified psychosocial problems reported fewer concerns. Older children are increasingly able to express their own concerns and thereby become an essential informant for the CHP. This may clarify some discrepancies between parents and CHPs in older children. Another explanation may be that, as the child grows older, parents have become more skilled in coping with the psychosocial problems of their child, leading to a reduction of parental concerns needing professional assistance. This may apply in particular to concerns about behavioral development, which were less often reported by parents of this age group (15\% versus $21 \%$ to $32 \%$ in the younger age groups).

\section{Strengths and limitations}

Strengths of the study are the size of the communitybased sample, and the availability of data from two types of informants. A limitation is that the non-response was higher for parents from non-industrialized countries and from one-parent households. However, because the percentage of CHP-identified problems did not differ between the response and non-response groups, the impact on the present findings seems limited. Another limitation is the use of parental self-reports to assess the child's psychosocial problem score, parental concerns and parenting efficacy. However, we used valid, reliable and frequently used questionnaires (i.e. the $\mathrm{CBCL}$ and ITSEA), which makes bias less likely [21-24]. A third limitation is that we did not obtain information on the process of the visit itself, i.e. whether or not parents discussed any problems with the CHP that led to a different evaluation. Although about $16 \%$ of the parents 'forgot' to complete the questionnaire before the visit and did it afterwards, and their level of agreement and presence of stressors did not differ from those parents who completed the questionnaire in advance.

We only included those parental concerns for which parents felt that they needed professional assistance; the 
present rates do not reflect all parents' concerns regarding their child's psychosocial development. This may have led to an underrepresentation of concerns of parents from non-industrialized countries, as they are less willing to talk about problems outside the direct family and, consequently, appear to need less professional assistance [39].

CHPs were not able to check the CBCL/ITSEA filled out by the parents. Therefore, it remains unknown what the agreement would have been had the CHPs been able to view the CBCL/ITSEA score. Nevertheless, a discrepancy between CHP and parents is still likely (even if they had viewed the CBCL/ITSEA), as professionals often do not use the recommended cut-off points of such instruments to guide their decisions [19]. Moreover, the sensitivity of CHPs in identifying children with problems on an assessment instrument when using a screening tool does not differ from that when they did not use such a tool [40]. In addition, the CHPs received instruction on interviewing parents about their socio-economic status and the mental health history of their child. Although the study did not provide training in the identification of psychosocial problems, conducting these interviews during the preventive health assessment may have had an impact on the CHPs' awareness and recognition of problems.

\section{Conclusions}

In the present study, the majority of children, parents and CHPs agree on whether or not the child has psychosocial problems. Nevertheless, there is disagreement regarding about one third of all children, mostly due to parental concerns not being confirmed by the CHP. Even when using screening instruments in the identification process, there will be some disagreement between parents and CHPs [19]. Future research should explore the parent-CHP interaction to further elucidate the decision-making process regarding the identification of psychosocial problems in children. In addition, the longer-term impact on uptake of treatment and psychosocial problems should be assessed to determine the efficacy of CHP-identified psychosocial problems.

\section{Funding}

This study was financially supported by the Netherlands Institute for Social Research (SCP).

\section{Availability of data and materials}

The dataset(s) supporting the conclusions of this article is available on request at the following e-mail address m.r.crone@lumc.nl.

\section{Authors' contribution}

MC participated in designing the data collection instruments, performed data collection and analyses, drafted the manuscript. EZ performed data collection, participated in designing the instruments, reviewed and revised the manuscript. SR conceptualized and designed the study, designed the data collection instruments, coordinated and supervised data collection, critically reviewed the manuscript. All authors approved the final manuscript as submitted.

\section{Competing interests}

The author(s) declare that they have no competing interests.

\section{Consent to publish}

Not applicable.

\section{Ethics}

The study was approved by the local Medical Ethical Committee of the Leiden University Medical Center, including the verbal informed consent by parents to the CHP. Parents received information about the study by mail prior to their visit to the CHP. Parents and CHPs filled out the questionnaires anonymously.

\section{Author details}

${ }^{1}$ Department of Public Health and Primary Care, Leiden University Medical Center, Public Health and Primary Care, P.O. Box 96002300 RC Leiden, The Netherlands. ${ }^{2}$ Province of Gelderland, Department of Youth Care, P.O. Box 90906800 GX Arnhem, The Netherlands. ${ }^{3}$ Department of Health Sciences, University Medical Center Groningen, University of Groningen, P.O. Box 1969700 AD Groningen, The Netherlands. ${ }^{4}$ TNO, Leiden, The Netherlands.

Received: 22 February 2015 Accepted: 16 May 2016

Published online: 19 May 2016

\section{References}

1. Tick NT, van der Ende J, Verhulst FC. Twenty-year trends in emotional and behavioral problems in Dutch children in a changing society. Acta Psychiatr Scand. 2007:116:473-82.

2. Ford T, Collishaw S, Meltzer H, Goodman R. A prospective study of childhood psychopathology: independent predictors of change over three years. Soc Psychiatry Psychiatr Epidemiol. 2007;42:953-61.

3. Hofstra MB, van der Ende J, Verhulst FC. Child and adolescent problems predict DSM-IV disorders in adulthood: a 14-year follow-up of a Dutch epidemiological sample. J Am Acad Child Adolesc Psychiatry. 2002;41:182-9.

4. Pierce EW, Ewing LJ, Campbell SB. Diagnostic status and symptomatic behavior of hard-to-manage preschool children in middle childhood and early adolescence. J Clin Child Psychol. 1999;28:44-57.

5. Smith JP, Smith GC. Long-term economic costs of psychological problems during childhood. Soc Sci Med. 2010;71:110-5.

6. Godoy L, Carter AS. Identifying and addressing mental health risks and problems in primary care pediatric settings: a model to promote developmental and cultural competence. Am J Orthopsychiatry. 2013;83:73-88.

7. Brugman E, Reijneveld SA, Verhulst FC, Verloove-Vanhorick SP. Identification and management of psychosocial problems by preventive child health care. Arch Pediatr Adolesc Med. 2001;155:462-9.

8. Sheldrick RC, Merchant S, Perrin EC. Identification of developmental-behavioral problems in primary care: a systematic review. Pediatrics. 2011;128:356-63.

9. Glascoe FP. Parents' evaluation of developmental status: how well do parents' concerns identify children with behavioral and emotional problems? Clin Pediatr (Phila). 2003;42:133-8.

10. Reijneveld SA, de Meer G, Wiefferink CH, Crone MR. Parents' concerns about children are highly prevalent but often not confirmed by child doctors and nurses. BMC Public Health. 2008;8:124.

11. Crone MR, Bekkema N, Wiefferink CH, Reijneveld SA. Professional identification of psychosocial problems among children from ethnic minority groups: room for improvement. J Pediatr. 2010;156:277-84.

12. Sheldrick RC, Neger EN, Perrin EC. Concerns about development, behavior, and learning among parents seeking pediatric care. J Dev Behav Pediatr. 2012;33:156-60.

13. Weitzman CC, Edmonds D, Davagnino J, Briggs-Gowan M. The association between parent worry and young children's social-emotional functioning. J Dev Behav Pediatr. 2011;32:660-7.

14. Sayal K, Taylor E. Detection of child mental health disorders by general practitioners. Br J Gen Pract. 2004;54:348-52.

15. Sayal K. Annotation: Pathways to care for children with mental health problems. J Child Psychol Psychiatry. 2006;47:649-59.

16. Tick NT, van der Ende J, Verhulst FC. Ten-year increase in service use in the Dutch population. Eur Child Adolesc Psychiatry. 2008;17:373-80. 
17. Yerkey TM, Wildman BG. Use of information about maternal distress and negative life events to facilitate identification of psychosocial problems in children. Fam Pract. 2004;21:261-5.

18. De Los Reyes A. Introduction to the special section: More than measurement error: Discovering meaning behind informant discrepancies in clinical assessments of children and adolescents. J Clin Child Adolesc Psychol. 2011:40:1-9

19. Hacker K, Goldstein J, Link D, Sengupta N, Bowers R, Tendulkar S, et al. Pediatric provider processes for behavioral health screening, decision making, and referral in sites with colocated mental health services. J Dev Behav Pediatr. 2013;34:680-7.

20. Horwarth J, Morrisson T. Identifying and implementing pathways for organizational change - using the Framework for the Assessment of Children in Need and their Families as a case example. Child Fam Soc Work. 2000:5:245-54.

21. Achenbach TM, Rescorla LA. Manual for the ASEBA preschool forms \& profiles. Burlington, VM: University of Vermont, Research Center for Children, Youth \& Families; 2000.

22. Achenbach TM, Rescorla LA. Manual for the ASEBA school-age forms \& profiles. Burlington, VT: University of Vermont, Research Center for Children, Youth, \& families; 2001.

23. Carter AS, Briggs-Gowan MJ. Infant Toddler Social and Emotional Assessment (ITSEA) manual. New Haven: Yale University, Department of Psychology; 2000.

24. Carter AS, Briggs-Gowan MJ, Jones SM, Little TD. The Infant-Toddler Social and Emotional Assessment (ITSEA): factor structure, reliability, and validity. J Abnorm Child Psychol. 2003;31:495-514.

25. Klein VM, Crone MR, Wiefferink CH, Reijneveld SA. Identification and management of psychosocial problems among toddlers by preventive child health care professionals. Eur J Public Health. 2010;20:332-8.

26. Achenbach TM, Rescorla LA. Multicultural Supplement to the Manual for the SEBA School-Age Forms \& Profiles. Burlington, VT: University of Vermont, Research Center for Children, Youth, \& families; 2007.

27. Bucx F. Family Report 2011.\{in Dutch\} The Hague. The Netherlands: Netherlands Research for Social Research; 2011.

28. Veerman JW, Janssen J, Kroes G, De Meyer R, Nguyen L, Vermulst A. Questionnaire on family functioning according to parents. The manual \{in Dutch\}. Nijmegen: Praktikon; 2012.

29. Villalonga-Olives E, Valderas JM, Palacio-Vieira JA, Herdman M, Rajmil L, Alonso J. The adaptation into Spanish of the Coddington Life Events Scales (CLES). Qual Life Res. 2008;17:447-52.

30. Coddington $\mathrm{RD}$. The significance of life events as etiologic factors in the diseases of children-II: A study of a normal population. J Psychom Res. 1972;16:205-13.

31. UNESCO Institute for Statistics. International Standard Classification of Education ISCED 2011. Montreal, Quebec: UNESCO Institute for Statistics; 2012.

32. Steele MM, Lochrie AS, Roberts MC. Physician identification and management of psychosocial problems in primary care. J Clin Psychol Med Settings. 2010;17:103-15.

33. Godoy L, Mian ND, Eisenhower AS, Carter AS. Pathways to service receipt. modeling parent help-seeking for childhood mental health problems. Adm Policy Ment Health. 2014;41:469-79.

34. Wichstrom L, Belsky J, Jozefiak T, Sourander A, Berg-Nielsen TS. Predicting service use for mental health problems among young children. Pediatrics. 2014;133:1054-60.

35. Teagle SE. Parental problem recognition and child mental health service use. Ment Health Serv Res. 2002:4:257-66.

36. Cox JE, Huntington N, Saada A, Epee-Bounya A, Schonwald AD. Developmental screening and parents' written comments: an added dimension to the parents' evaluation of developmental status questionnaire. Pediatrics. 2010;126 Suppl 3:S170-6.

37. Alexander KE, Brijnath B, Mazza D. Can they really identify mental health problems at the age of three? 'Parent and practitioner views about screening young children's social and emotional development. Aust N Z J Psychiatry. 2013;47:538-45.

38. Blanchard LT, Gurka MJ, Blackman JA. Emotional, developmental, and behavioral health of American children and their families: a report from the 2003 National Survey of Children's Health. Pediatrics. 2006;117:e1202-12.
39. Zwirs BWC, Burger H, Schulpen TWJ, Buitelaar JK. Different treatment thresholds in non-western children with behavioral problems. J Am Acad Child Adolesc Psychiatry. 2006;45:476-83.

40. Mieloo C. Early detection and referral of young children with psychosocial problems in the preventive child health care. Rotterdam, The Netherlands: Dissertation edn. Erasmus University Rotterdam; 2014.

\section{Submit your next manuscript to BioMed Central and we will help you at every step:}

- We accept pre-submission inquiries

- Our selector tool helps you to find the most relevant journal

- We provide round the clock customer support

- Convenient online submission

- Thorough peer review

- Inclusion in PubMed and all major indexing services

- Maximum visibility for your research

Submit your manuscript at www.biomedcentral.com/submit
Biomed Central 